\title{
Global systems approach to bacterial physiology: protein responders to stress and starvation
}

\author{
R.A. VanBogelen and F.C. Neidhardt \\ Department of Microbiology and Immunology, University of Michigan Medical School, Ann Arbor, MI, U.S.A.
}

Key words: Regulon; Stimulon; Stress; Two-dimensional gels; Alarmones; Cellular databases

\section{INTRODUCTION}

For over a century microbial physiologists have been studying how bacteria adapt and grow in their environment. A tremendous amount of information has been obtained by two quite different approaches. One approach studies how the bacterium as a biological system competes with other bacterial species for the limiting nutrient supply [1-4] and also how is survives deleterious environmental conditions [2-5]. Another approach studies the individual enzymes necessary for the cell to survive or compete successfully in its environment and how the individual genes for these enzymes are regulated (for example, see $[6,7])$.

A more recent strategy, the global systems approach, has been developed which helps to link these two classical approaches by allowing the investigator to study the response of many genes/ proteins simultaneously. By this strategy one identifies the sets of genes/proteins which respond to an environmental condition and then uncovers the regulatory elements that unite these sets of genes/ proteins. For some multigene systems this approach has helped to elucidate in molecular terms

Correspondence to: F.C. Neidhardt, Department of Microbiology and Immunology, University of Michigan Medical School, Ann Arbor, MI 48109-0620, U.S.A. how the cell senses and triggers the response, and has been useful also in determining the significance of this response for the survival of the biological system. The primary tool for the global systems approach is two-dimensional polyacrylamide gel electrophoresis, which allows examination of the pattern of gene expression of the whole cell as revealed by the level of individual proteins. When combined with other genetic and biochemical techniques this approach can significantly advance the understanding of how biological systems function.

Several descriptions of the global systems approach have been written $[8,9]$. The following sections discuss its use through examples of global systems which are being characterized in the bacterium Escherichia coli. The final section deals with how the massive amounts of information obtained from this approach can be managed to advance the understanding of the physiology of a biological system.

\section{RESULTS AND DISCUSSION}

\subsection{Identifying protein responders}

Two-dimensional polyacrylamide gel electrophoresis (PAGE) separates proteins by two different pioperties, their charge and their molecular mass. Four different 2-D gel formats have been described, the mini-gel, the O'Farrell gel [10,11], 
the Garrels gel [12], and the giant gel [13] methods. All four use isoelectric focusing in the first dimension and SDS-PAGE in the second dimension. The four differ in the physical dimensions and total protein capacity of the gels and the number of protein spots resolved. Apparatus for all but the giant gel method are commercially available from more than one source, and an increasing number of chemical suppliers are offering specially made, pre-mixed, and even quality controlled chemicals for 2-D gels. The optimal situation for global systems analysis is to have 2-D gels which are of very high quality and are reproducible so that the response of each individual protein (often called a spot on the 2-D gel) can be reliably recorded for different experimental conditions and by different groups of investigators (as discussed in [14]).

Spot detection can be by direct staining and autoradiography. Protein samples can be stained with Coommasie Blue [10], or with a more sensitive silver staining process [15,16]. Radiolabeled proteins (using ${ }^{32} \mathrm{P},{ }^{14} \mathrm{C},{ }^{35} \mathrm{~S}$ and ${ }^{3} \mathrm{H}$ ) can be detected by exposing the gel to X-ray film. Fluorographic methods are used to enhance the detection of low energy emitting ${ }^{3} \mathrm{H}$ or to decrease the exposure time needed for the other isotopes [17]. Radiolabeling of proteins can be used to determine rates of synthesis of individual proteirss [18], or to view the gene expression (through the protein products) under specific conditions $[19,20]$ or at specific times [21].

Changes in the levels or rates of synthesis of proteins can be qualitatively observed by visually comparing different gels [22] or can be quantitatively measured by two different techniques, (i) cutting the protein spot out of the gel and counting the amount of radioactivity [18,21], or (ii) using specially designed computer programs that determine density levels on X-ray films (e.g. [23]).

In $E$. coli the global system approach has been used extensively to characterize (qualitatively and quantitatively) the response to a variety of different environmental conditicns. Some studies report changes in the levels of individual proteins under different growth condition $[19,20]$, others report changes in the rates of synthesis following abrupt changes in some growth parameter $[18,21]$ and still other list proteins which respond to a single stress condition (so-called, unique responders) and those that respond to several stress conditions (shared responders) $[21,24]$.

\subsection{Discovery of regulatory networks}

The initial step in the global systems approach is to group proteins by their response. In some very simple cases the genes for these proteins are found in an operon, a single transcriptional unit, which is probably the simplest solution to the problem of co-regulation of genes (although there are numerous examples of operons whose protein products are not equimolar (e.g. [25]). Many environmental stimuli elicit the response of a very large group of proteins [21] whose genes are not cotranscribed. The term stimulon is used to describe such a group [8]. A stimulon is almost always first recognized using 2-D gels and the

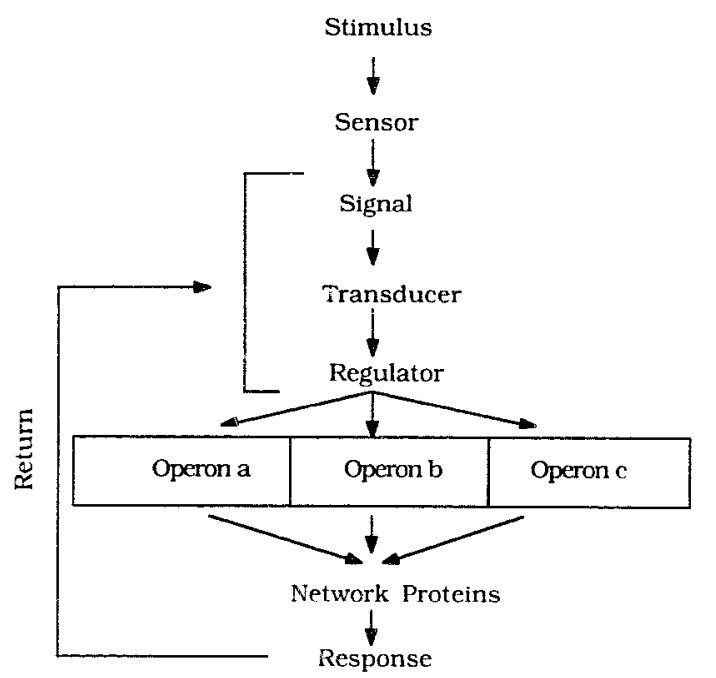

Fig. 1. Generic diagram of stimulus-response network. This diagram begins with a stimulus from the environment and illustrates the pathway to the response. The sensor is the cellular target affected by the stimulus, the signal is generated by the sensor, the transducer transmits the signal to the regulator by affecting the synthesis or activity of the regulator, the regulator controls the output (this illustration depicts a transcriptional regulator where the output is genes/proteins, but the output could be any cellular molecule(s)), the response is usually some adaptive response to the environmental condition, and the return is the feedback mechanism for turning the response off. 
term does not imply that the genes for these proteins share regulatory elements, only that they respond to the same stimulus. The term regulon, which was first used for the arg genes, is used for groups of operons that share a common regulatory element and its effector ligands, and are often defined using mutant strains with a defective regulatory element [8]. Some investigators prefer to reserve the term regulon for a group of operons that concern a single metabolic pathway and that are co-regulated by means of a common repressor or activator. For operons that span many pathways and that have separate regulator proteins as well as a shared ones, the term modulon has been proposed [8]. More useful is the term, regulatory network, or stimulus-response network, a more generic term that can refer to groups of co-regulated proteins or genes no matter what the details of their regulation [8].

Fig. 1 displays a generic structure of a stimulus-response network. The stimulus is the environmental condition (starvation, a harmful chemical, etc.), the sensor is the cellular molecule or macromolecule which senses the stimulus and produces a signal which affects the tranisducer(s). The transducer affects the activity or synthesis of the regulator. The regulator controls the genes/ proteins which constititute the response. Most networks have a feedback mechanism, a return, which brings the system back to the pre-stimulus condition or to a new equilibrium state appropriate for the new environment [8].

Fig. 2 displays three examples of stimulus-response networks arranged to reveal their common structure. These examples also include the three major types of network regulators: those with repressors, those with activators, and those with an altered subunit (sigma subunit in prokaryotes) composition of RNA polymerase (some networks use a combination of these). Most of the prokaryotic regulators discovered so far are DNA binding proteins that affect the initiation of transcription of the genes in the network (discussed in [26]), but the regulator could control the system at other levels, including termination and translation of mRNA, stability or processing of the polypeptide product, and chemical modifications which affect the activity of the network proteins. There are many examples of operons controlled at the translational level (e.g. $[27 \mathrm{j}$ ), but no examples of regulators that adjust the translation of pre-existing mRNA. There are also no known examples yet of a regulator affecting the stability or processing of the network proteins. In the chemotaxis net-
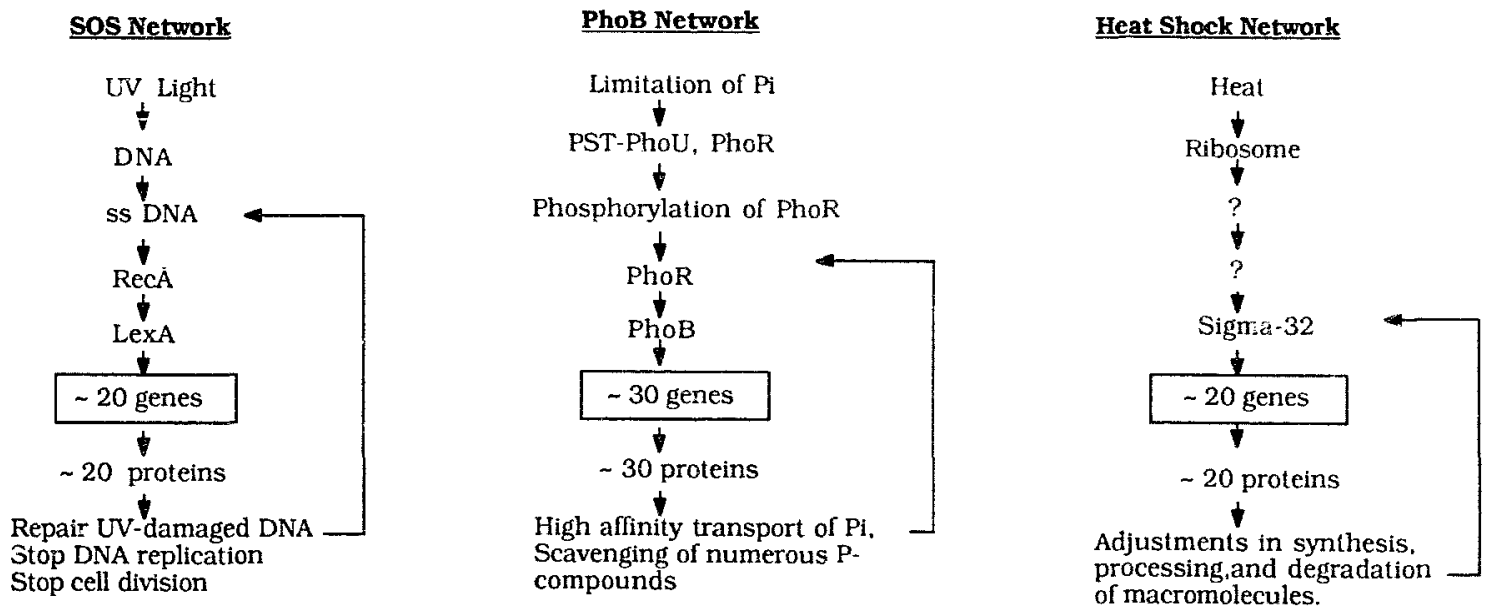

Fig. 2. Examples of stimulus-response networks. Most of the responses to environmental conditions can be described using the generic diagram in Fig. 1. The responses to three conditions, UV light, limitation of inorganic phosphate, and heat, are illustrated. These three networks represent examples of the three types of transcriptional regulators which have been described. The SOS network uses a negative regulator, LexA (reviewed in [29]); the PhoB network uses a positive regulator, PhoB (reviewed in [28]); the heat shock network uses a unique transcription factor, Sigma-32 (reviewed in $[30,31]$ ). 
work the regulator controls the degree of chemical modification of the network proteins. In its active form this regulator (CheB) acts to deamidate or demethylate the membrane receptor-transducer proteins (reviewed in [28]).

Two-dimensional gel analysis of mutants in regulatory elements helps determine the number of genes/proteins which belong to each regulon. Some regulons were initially characterized by the analysis of such mutant strains (e.g. the heat shock response [22]), while other regulons have been extensively characterized for one (or maybe a few) members of a regulon (e.g. the regulon to which alkaline phosphate belongs [6]). This analysis has also been used to demonstrate that some stimuli induce more than one regulon (e.g. [32]).

\subsection{Solving the mechanisms of sensing and trigger- ing}

The sensing and triggering mechanisms are perhaps the most difficult parts of any stimulus-response network to ascertain. The mechanisms for only a few systems are well defined (SOS [29], chemotaxis [28], nitrogen starvation [28] and phosphate starvation [28]). The global system approach was not used to help elucidate the mechanisms in these systems. For other networks (i.e. the heat shock [30,31], oxidation stress [32,33], carbon starvation networks [34]) the global systems approach has been the primary method to determine what is known about the sensory and triggering mechanisms.

The global systems approach is often used to test if any well known signaling molecules, like cAMP-CAP (e.g. [34]), guanosine tetraphosphate (e.g., [21]), and adenylylated nucleotides (e.g. $[21,33])$ regulate particular proteins or groups of proteins. Two methods are commonly used: learning whether the proteins respond differently in mutants altered in these proteins or in proteins that synthesize these 'alarmones' [34,35], and learning whether the 2-D gel pattern of protein synthesis always correlates with the level of the alarmones [21,33].

The global systems approach offers one the potential to study the sensing and triggering mechanism directly, because it allows one to sort out overlapping responses to different environ- mental conditions. For example, a very large number of conditions induce some or all of the proteins of the heat shock network (the sigma-32 regulon). Careful analysis of these conditions has revealed that most induce only a subset of the network proteins, and that for some conditions that induce the entire heat shock network the induction is a minor part of the cell's total response. The only conditions that induce the heat shock network as the major response are known to affect the translational capacity of the cell. Tests of this idea, using antibiotics which target the ribosome, have supported the interpretation that heat shock is related to translational capacity [31]. Future studies using various biochemical and genetic experiments (together with more tests using 2-D gels) can be designed to confirm these ideas.

\subsection{Learning the function of stimulus-response net- works}

Stimulus-response networks can for the most part be placed into one of four categories of function: (i) response to nutrient limitation, (ii) response to changes in energy metabolism, (iii) repair of damage caused by environmental agents nd (iv) major change in the physiology or mor- ology of the cell in response to prolonged suboptimal environmental conditions (reviewed in [8]).

The global systems approach can be used to determine the function of a response by identifying the responders as proteins with a previously characterized function, or by studying the phenotype of mutants in the genes that encode these proteins. There are numerous ways to identify proteins, some are listed below. Ideally, more than one of these methods are used to determine which spot corresponds to a protein or gene.

- Purified proteins can be comigrated with labeled cellular extracts to determine where the protein migrates on the gel [36].

- Cloned genes can be preferentially expressed and their proteins labeled with radiolabeled amino acids using a variety of methods (maxi cells [37], mini cells [38], chloramphenicol amplification [39] and expression, and overproduction of the protein by directing the transcription of the gene by an inducible promoter [40-42]). 
- Genes with well-characterized mutants can be analyzed using 2-D gels to determine the location of its protein product. Deletion, insertion or nonsense mutants are most effective, since the protein will be missing on the 2-D gel. Some missense mutants affect the migration of the protein by changing the overall charge of the protein $[43,44]$. - The proteins which are enzymes in inducible or repressible pathways can often be identified on 2-D gels, for example the enzymes in the methionine biosynthetic pathway are strongly repressed in the presence of exogenous metitonine (reviewed in [45!).

- A protein spot can be characterized by 'reverse genetics'. The spot is cut out of the 2-D gel, partially sequenced, and the corresponding gene cloned by Southern hybridization of a oligonucleotide (made from the information learned by the partial sequencing) to a genomic library, and mutated by directed mutagenesis (e.g. [46]).

- The molecular weight and the $\mathrm{p} I$ of a protein can be calculated from the amino acid sequence predicted from the DNA sequence of a gene. Using these numbr rs the approximate location on the 2-D gel can be predicted for the protein [47].

\subsection{Cataloging the responses to stimuli}

The global systems approach generates massive amounts of information. A 2-D gel can resolve up to 2500 protein spots. Early methods used to record locations of spots on 2-D gels involved establishing a reference gel. This reference gel was overlayed with a fine grid which enabled each spot to be assigned a unique $X$ and $Y$ coordinate [36]. Each experimental gel was then compared with the reference gel for assignment of coordinates. Computer software programs (commercially available as well as public domain) are now available which reduce the person-hours required to match each spot to the reference gel. Each investigator must choose what spots are of interest. If the response of only a small number of the spots is recorded in any global study, then massive amounts of information are lost with each 2-D gel, but without computer assisted analysis it is unthinkable to record the response of each spot.

The concept of a cellular protein database has emerged from studies using 2-D gels. The ideal

\section{Neidhardt Lab E. coli Database}

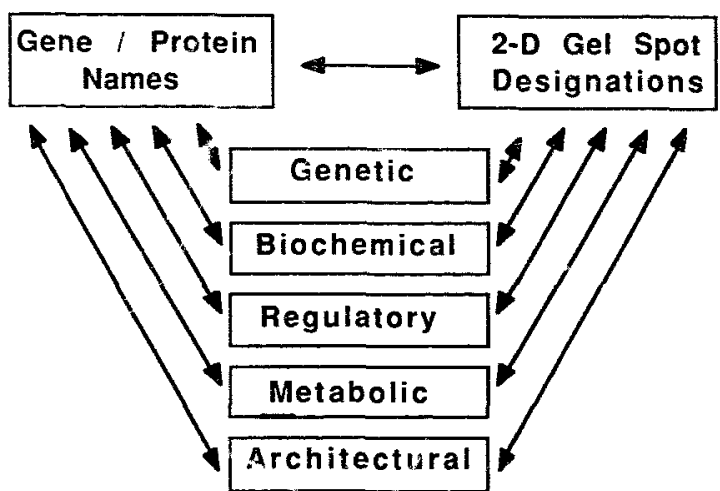

Fig. 3. Structure of a genomicaily linked database. The information obtained from 2-D gels can be used to generate a genomically linked database when a protein spot on the 2-D gel is identified as the product of a single gene (e.g. [48]). Other information can be gathered about genes/proteins and protein spots; genetic-where the gene is located on the chromosome and whether the gene is cloned, biochemical-physical and enzymatic properties of the protein, regulatory-how the gene/protein is regulated either in molecular terms (regulators and effector ligands) or in global terms (conditions which affect the level of the protein), metabolic-what metabolic pathway or cellular process the protein is part of, and architectural-the cellular location of the protein and the macromolecular structure to which the protein belongs.

cellular database should be genomically linked, tracing each protein to its structural gene and accounting for every structural gene of the cell. However, any attempt (with or without computer assistance) to catalog information on 2-D gel spots can serve as the beginning of a database for modeling biological systems. Examples of such cataloging exist for several biological systems [48-50]. Fig. 3 presents the structure of a senomically linked database. Perhaps the most important link is the identification of the protein spot on a 2-D gel with a known gene or previously characterized protein. Other information can be collected as well, bringing together information obtained from many types of studies-structural, genetic, biochemical, metabolic and physiological.

A central goal in biology is figuring out how cells grow. The global systems approach makes use of a nearly complete picture of the cell's complement of proteins and patterns of gene ex- 
pression through the use of 2-D gels. It permits analysis of complex cellular properties and the discovery of ceilular regulatory networks. This approach lays the groundwork for future developments in cell modeling.

\section{ACKNOWLEDGEMENTS}

Work on global systems analysis and database development in the authors' laboratory is supported in part by grants to FCN from the National Science Foundation (DMB-8903787) and the National Institute of Fiealth (GM17892).

\section{REFERENCES}

[1] Gottschal, J.C. (1985) Some reflections on microbial competiveness among heterotrophic bacteria. Antonie Van Leeuwenhoek 51, 473-494.

[2] Koch, A.L. (1971) The adaptive responses of Escherichia coli to a feast and famine existence. Adv. Microb. Physiol. $6,147-217$.

[3] Koch, A.L. (1985) The macroeconomics of bacterial growth, in Bacteria in their Natural Environments (Fletcher, M.M. and Floodgate, G.D., Eds.), Symb. Soc. Gen. Microb. 35, 1-42.

[4] Koch, A.L. (1988) Why can't a cell grow infinitely fast? Can. J. Microbiol. 34, 421-426.

[5] Kjelleberg, S., Hermansson, M., Mårdén, P. and Jones, G.W. (1987) The transient phase between growth and nongrowth of heterotrophic bacteria, with emphasis on the marine environment. Annu. Rev. Microbiol. 41, 25-49.

[6] Torriani-Gorini, A., Rothman, F., Silver, S., Wright, A. and Yagil, E. (Eds.) (1987) Phosphate Metabolism and Cellular Regulation in Microorganisms. American Society for Microbiology, Washington.

[7] Kustu, S., Sei, K. and Keener, J. (1986) Nitrogen regulation in enteric bacteria, in Regulation of Gene Expression. Symposium of the Society for General Microbiology (Booth, I. and Higgin, C., Eds.), pp. 139-154. Cambridge University Press, Cambridge.

[8] Neidhardt, F.C., Ingraham, J.L. and Schaechter, M. (1990) Physiology of the Bacterial Cell, pp. 351-388. Sinauer Associates, Inc., Sunderland.

[9] Gottesman, S. (1984) Bacterial regulation: global regulatory networks. Annu. Rev. Genet. 18, 415-441.

[10] O'Farrell, P.H. (1975) High resolution two-dimensional electrophoresis of proteins. J. Biol. Cher. 250, $4007 \ldots 4021$.

[11] O'Farrell, P.Z., Goodman, H.M. and O'Farrell, P.H. (1977) High resolution two-dimensional electrophoresis of basic as well as acidic proteins. Cell 12, 1133-1142.
[12] Garrels, J.I. (1983). Quantitative two-dimensional gel electrophoresis of proteins. Methods Enzymol. 100, 411-423.

[13] Young, D.A., Voris, B.P., Maytin, E.V. and Colbert, R.A. (1983) Very-high-resolution two-dimensional electro. phoresis separation of proteins on giant gels. Methods Enzymol. 91, 190-214.

[14] Neidhardt, F.C. (1989) Report of workshop on cellular protein databases derived from two-dimensional polyacrylamide gel electrophoresis. Electrophoresis 10, 73-75.

[15] Switzer, R.C., Merrill, C.R. and Shifrin, S. (1979) A highly sensitive silver stain for detecting proteins and peptides in polyacrylamide gels. Anal. Biochem. 98, 231 - 237.

[16] De Moreno, M.R., Smith, J.F. and Smith. R.V. (1985) Silver staining of proteins in polyacrylamide gels: increased sensitivity through a combined Coommasie bluesilver stain procedure. Anal. Biochem. 151, 466-470.

[17] Bonner, W.M. and Laskey, R.A. (1974) A film detection method for tritium-labeled proteins and nucleic acids in polyacrylamide gels. Eur. J. Biochem. 46, 83-88.

[18] Lemaux, P.G., Herendeen, S.I., Bloch, P.L. and Neidhardt, F.C. (1976) Transient rates of synthesis of individual polypeptides in $E$. coli follow ng temperature shifts. Cell 13, 427-434.

[19] Petersen, S., Bloch, P.L., Reeh, S and Neidhardt, F.C. (1978) Patterns of protein synthesis $i_{i}: E$. coli: a catalog of the amount of 140 individual proteins it difierent growth rates. Cell 14, 1\%9-190.

[20] Herendeen, S.L., VanBogelen, R.A. and Neidhardt, F.C. (1979) Levels of major proteins of Escherichia coli during growth at different temperatures. J. Bacteriol. 139, 185-194.

[21] VanBogelen, R.A., Kelley, P.M. and Neidhardt, F.C. (1987) Differential induction of heat shock, SOS, and oxidation stress regulons and accumulation of nucleotides in Escherichia coli. J. Bacteriol. 169, 26-32.

[22] Neidhardt, F.C. and VanBogelen, R.A. (1981) Positive regulatory gene for temperature-controlled proteins in Escherichia coli. Biochem. Biophys. Res Commun. 100, 894-900.

[23] Garrels, J.1. (1989) The QUEST system for quantitative analysis of two-dimensional gels. J. Biol. Chem. 264, $5269-5282$.

[24] Groat, R.G., Schultz, J.F., Zychlensky, E., Bockman, A. and Matin, A. (1986) Starvation proteins in Escherichia coli: Kinetics of synthesis and role in starvation survival. J. Bacteriol. 168, 486-493.

[25] Miller, J.H. and Reznikoff, W.S. (Eds.) (1978) The Operon. Cold Spring Harbor Laboratory, Cold Spring Harbor.

[26] Magasanik, B. (1989) Gene regulation from sites near and far. The New Biologist 1, 247-251.

[27] Jinks-Robertson, S. and Normura, M. (1987) Ribosomes and tRNA, in Escherichia coli and Salmonella typhimurium: Cellular and Molecular Biology, (Neidhardt, F.C., Ingraham, J.L., Low, 5.L., Magasanik, B.. Schaecter, M. and Umbarger, H.E., Eds.), pp. 1353-1385. American Society for Microbiology, Washington. 
[28] Stock, J.B., Ninfa, A.J. and Stock, A.M. (1989) Protein phosphorylation and regulation of adaptive responses in bacteria. Microbiol. Rev. 53, 450-490.

[29] Walker, C.C. (1987) The SOS response, in Escherichia coli and Salmonella typhimurium: Cellular and Molecular Biology (Neidhardt, F.C., Ingraham, J.L., Low. B.L., Mas asanik, B., Schaecter, M. and Umbarger, H.E., Eds.), pp. 1346-1357. American Sociecy for Microbiology. Washington.

[30] Neidhardt, F.C. and VanBogelen, R.A. (1987) Heat shock response, in Escherichia coli and Salmonella typhimurium: Cellular and Molecular Biology (Neidhardi, F.C., Ingraham, J.L.. Low, B.L., Magasanik, B., Schaecter, M. and Umbarger, H.E., Eds.), pp. 1334-1345. American Society for Microbiology, Washington.

[31] VanBogelen, R.A. and Neidhardt, F.C. (1990) Ribosomes as sensors of heat and cold shock in Escherichia coli. Pror. Natl. Acad. Sci. USA 87, 5589-5593.

[32] Christman, M.F., Morgan, R.W., Jacobson, F.S. and Ames. B.N. (1985) Positive control of a regulon for defenses against oxidation stress and some heat-shock proteins in Salmonella typhimurium. Cell 41, 753-762.

[33] Lee, P.C., Bochner, B.R. and Ames, B.N. (1983) AppppA. heat shock, stress, and cell oxidation. Proc. Natl. Acad. Sci. USA 80, 7496-7500.

[34] Schultz, J.E., Latter, G.I. and Matin, A. (1988) Differential regulation by cyclic AMP of starvation proteins synthesized in Escherichia coli. J. Bacteriol. 170, 39033909.

[35] Grossman, A.D., Taylor, W.E., Burton, Z.F., Burgess. R.R. and Gross, C.A. (1985) Stringent response in Escherichia coli induces expression of heat shock proteins. J. Mol. Biol. 186, 357-365.

[36] Bloch, P.L., Phillips, T.A. and Neidhardt, F.C. (1980) Protein identifications on O'Farrell two-dimensional gels: Locations of 81 Escherichia coli proteins. J. Bacteriol. 141, 1409-1420.

[37] Sancar, A., Hach, A.M. and Rupp, W.D. (1979) Simple method for identification of plasmid-coded proteins. J. Bacteriol. 137, 692-693.

[38] Reeve, J. (1979) Use of minicells for bacteriophage directed polypeptide synthesis. Methods Enzymol. 68, 493503.

[39] Neidhardt, F.C., Wirth. R. Smith, M.W. and VanBogelen. R.A. (1980) Selective synthesis of plasmid-coded proteins by Escherichia coli during recovery from chloramphenicol treatment. J. Bacteriol. 143, 535-537.

[40] Studier, F.W. and Moffatt, B.A. (1986) Use of hacteriophage T7 RNA polymerase to direct selective high-level expression of cloned genes. J. Mol. Biol. 189. 113-130.
[41] DeBoer. H.A., Comstock, L.J.. Yansura, D.G. and Heynecker. H.L. (1982) Construction of a tandem trp-lac promoter and a hybrid trp-lac promoter for efficient and controlled expression of the human growth hormone in Escherichia coli, in Promoters: Structure and Function (Rrdriguez, R.L. and Chamberlain, M.J., Eds.), pp. 462 482. Praegar Publishers, New York

[c] Hedgpeth, J., Ballevet, M. aná Eisen, H (1978) Lambda phage promoter user to enhance expression of a plasmidcloned gene. Mol. Gen. Genet. 163, 197-203.

[43] Neidhardt, F.C., Phillips, T.A., VanBogelen, R.A., Smith. M.W., Georgalis, Y. and Subramanian, A.R. (1981) Identity of B56.5 protein. the A-protein, and the groE gene product of Escherichia coli. J. Bacteriol. 145, 513-520.

[44] Tilly, K., VanBogelen, R.A., Georgopoulos. C. and Neidhardt. F.C. (1983) Identification of the heat-inducible protein C15.4 as the groES gene product in Escherichia coli. J. Bacteriol. 154, 1505-1507.

[45] Cohen, G.N. and Saint-Girons, I. (1987) Biosynthesis of theonine, lysine and methionine, in Escherichia coli and Salmonella typhimurium: Cellular and Molecular Biology (Neidhardt, F.C.. Ingraham, J.L., Low, B.L., Magasanik, B. Schaechter, M. and Umbarger, H.E., Eds.), pp. $42{ }^{\circ}$ 444. American Society for Microbiology, Washington.

[46] Goldstein, J., Pollitt, N.S and Inouye, M. (1990) Major cold shock protein of Escherichia coli. Proc. Natl. Acad. Sci. USA 87, 283-287.

[47] Neidhardt, F.C., Appleby, D.A., Sankar, P.. Hutton, M.E. and Phillips, T.A. (1989) Genomically linked cellular databases derived from two-dimensional polyacrylamide gels electrophoresis. Electrophoresis 10, 116-121.

[48] Phillips, T.A., Vaughn, V., Bloch, P.L, and Neidhardt. F.C. (1987) Gene-protein index of Escherichia coli K-12. Edition 2, in Escherichia coll and Salmonella typhimurium: Cellular and Molecular Biology (Neidhardt. F.C., Ingraham. J.L., Low, B.L, Magasanik. B., Schaechter, M. and Umbarger, H.E., Eds.). pp. 919-966. American Society for Microhiclogy, Washington.

[49] Garrels, J.I. and Franza, B.R. (1989) The REF52 protein database. Methods or database construction and analysis using the QUEST swstem and characterizations of protein patterns from proliferating and quescent REF52 cells. $J$ Biol. Chem. 264, 5283-5298.

[50] Celis, J.E., Ratz. G.P., Madsen, P.. Gesser, B., Lauridsen, J.B., Brogaard Hansen. K.P.. Kwee. S., Holm Rasmussen, H., Nielsen, H.V., Cruger, D., Basse, B., Leffers, H., Honore, B., Moller, O. and Celis, A (1989) Computerized, comprehensive databases of cellular and secreted proteins from normal human embrvonic lung MRC-5 fibroblasts: Identification of transiomation and/ or proliferation sensitive proteins. Electrophoresis 10, 76-115. 